\title{
Genome sequence of the orange-pigmented seawater bacterium Owenweeksia hongkongensis type strain (UST20020801 ${ }^{\mathrm{T}}$ )
}

\author{
Thomas Riedel ${ }^{1}$, Brittany Held ${ }^{2,3}$, Matt Nolan ${ }^{2}$, Susan Lucas ${ }^{2}$, Alla Lapidus ${ }^{2}$, Hope Tice ${ }^{2}$, \\ Tijana Glavina Del Rio ${ }^{2}$, Jan-Fang Cheng' ${ }^{2}$ Cliff Han $^{2,3}$, Roxanne Tapia ${ }^{2,3}$, Lynne A. \\ Goodwin $^{2,3}$, Sam Pitluck², Konstantinos Liolios ${ }^{2}$, Konstantinos Mavromatis ${ }^{2}$, Ioanna Pagani ${ }^{2}$, \\ Natalia Ivanova ${ }^{2}$, Natalia Mikhailova ${ }^{2}$, Amrita Pati ${ }^{2}$, Amy Chen $^{4}$, Krishna Palaniappan ${ }^{4}$, \\ Manfred Rohde', Brian J. Tindall ${ }^{6}$, John C. Detter ${ }^{2,3}$, Markus Göker ${ }^{6}$, Tanja Woyke ${ }^{2}$, James \\ Bristow $^{2}$, Jonathan A. Eisen ${ }^{2,7}$, Victor Markowitz ${ }^{4}$, Philip Hugenholtz ${ }^{2,8}$, Hans-Peter Klenk ${ }^{6^{*}}$, \\ and Nikos C. Kyrpides ${ }^{2}$ \\ ${ }^{1}$ HZI - Helmholtz Centre for Infection Research, Braunschweig, Germany \\ ${ }^{2}$ DOE Joint Genome Institute, Walnut Creek, California, USA \\ ${ }^{3}$ Los Alamos National Laboratory, Bioscience Division, Los Alamos, New Mexico, USA \\ ${ }^{4}$ Biological Data Management and Technology Center, Lawrence Berkeley National \\ Laboratory, Berkeley, California, USA \\ ${ }^{5}$ Oak Ridge National Laboratory, Oak Ridge, Tennessee, USA \\ ${ }^{6}$ Leibniz Institute DSMZ - German Collection of Microorganisms and Cell Cultures, \\ Braunschweig, Germany \\ ${ }^{7}$ University of California Davis Genome Center, Davis, California, USA \\ ${ }^{8}$ Australian Centre for Ecogenomics, School of Chemistry and Molecular Biosciences, The \\ University of Queensland, Brisbane, Australia
}

*Corresponding authors: Hans-Peter Klenk (hpk@dsmz.de)

Keywords: aerobic, motile, rod-shaped, mesophilic, non-fermentative, Gram-negative, orange-pigmented sea water, Bacteroidetes, Flavobacteria, Cryomorphaceae, GEBA

Owenweeksia hongkongensis Lau et al. 2005 is the sole member of the monospecific genus Owenweeksia in the family Cryomorphaceae, a poorly characterized family at the genome level thus far. This family comprises seven genera within the class Flavobacteria. Family members are known to be psychrotolerant, rod-shaped and orange pigmented ( $\beta$-carotene), typical for Flavobacteria. For growth, seawater and complex organic nutrients are necessary. The genome of $O$. hongkongensis UST20020801 ${ }^{\top}$ is only the second genome of a member of the family Cryomorphaceae whose sequence has been deciphered. Here we describe the features of this organism, together with the complete genome sequence and annotation. The 4,000,057 bp long chromosome with its 3,518 protein-coding and 45 RNA genes is a part of the Genomic Encyclopedia of Bacteria and Archaea project.

\section{Introduction}

Strain UST20020801 ${ }^{\mathrm{T}}$ (= DSM 17368 = NRRL B$23963=$ JCM 12287) is the type strain of the species Owenweeksia hongkongensis [1] in the monotypic genus Owenweeksia [1]. The genus was named after Owen B. Weeks for his work on Flavobacterium and Cytophaga during the 1950s to 1970s [1]. The species epithet points to Hong Kong, P. R. China, the place where the stain was isolated [1]. Strain UST20020801 ${ }^{\mathrm{T}}$ was first isolated in August 2002 from seawater samples collected from Port Shelter in Hong Kong during a study of the bacterial diversity in Hong Kong coastal sea water. Members of the phylum Bacteroidetes are widely distributed in marine and freshwater ecosystems. Compared to free-living bacteria, they were more frequently attached to aggregates [2,3] and occurred during algae blooms [4,5]. Representatives of the phylum Bacteroidetes, especially of the class Flavobacteria, are well-known to efficiently degrade and consume high-molecular-mass organic matter [6-11]. Recently, the family Cryomorphaceae was proposed to constitute a branch within the 
phylum Bacteroidetes [12]. This family encompasses the marine genera Brumimicrobium, Cryomorpha, Crocinitomix [12], Owenweeksia [1], Lishizhenia [13], Wandonia [14], and "Phaeocystidibacter" [15] as well as the freshwaterliving genus Fluviicola [16]. Here we present a summary classification and a set of features for $O$. hongkongensis UST20020801 , together with the description of the genomic sequencing and annotation.

\section{Classification and features}

A representative genomic $16 \mathrm{~S}$ rRNA sequence of $O$. hongkongensis UST20020801 ${ }^{\mathrm{T}}$ was compared using NCBI BLAST $[17,18]$ under default settings (e.g., considering only the high-scoring segment pairs (HSPs) from the best 250 hits) with the most recent release of the Greengenes database [19]. The relative frequencies of taxa and keywords (reduced to their stem [20]) were determined, weighted by BLAST scores. The only named genus in the list was Owenweeksia (1 hit in total). Regarding the single hit to a sequence from members of the species, the average identity within HSPs was 99.9\%, whereas the average coverage by HSPs was $99.8 \%$. No hits to sequences with other species names were found. (Note that the Greengenes database uses the INSDC (= EMBL/NCBI/DDBJ) annotation, which is not an authoritative source for nomenclature or classification.) The highest-scoring environmental sequence was EU328017 ('dynamics during bioremediation crude oil contaminated moderate saline soil clone B76'), which showed an identity of $93.2 \%$ and an HSP coverage of $99.9 \%$. The most frequently occurring keywords within the labels of all environmental samples which yielded hits were 'marine' (3.0\%), 'lake' (2.9\%), 'depth' (2.7\%), 'water' (2.6\%) and 'zone' (2.5\%) (249 hits in total) and corresponded with the habitat from which strain UST $20020801^{\mathrm{T}}$ was isolated.

Figure 1 shows the phylogenetic neighborhood of 0 . hongkongensis in a 16S rRNA based tree. The sequences of the two identical 16S rRNA gene copies in the genome do not differ from the previously published 16S rRNA sequence (AB125062).

O. hongkongensis UST20020801 ${ }^{\mathrm{T}}$ is a Gramnegative, halophilic, non-flagellated, motile, and rod-shaped bacterium (Figure 2) [1]. Colonies are orange, convex, smooth, glistening and translucent with an entire margin [1]. Cells are 0.3-0.5 $\mu \mathrm{m}$ in width and 0.5-4.0 $\mu \mathrm{m}$ in length [1]. The strain does not sporulate [1]. Cells are strictly aerobic heterotrophs requiring $\mathrm{Na}^{+}, \mathrm{Mg}^{2+}$, sea salts and yeast extract or peptone for growth [1]. Growth occurs between $4^{\circ} \mathrm{C}$ and $37^{\circ} \mathrm{C}$ with an optimum at $25^{\circ} \mathrm{C}-33^{\circ} \mathrm{C}$ [1]. The $\mathrm{pH}$ range for growth is 5.2-9.0 with an optimum at $\mathrm{pH} 6.0-8.0$ [1]. The salinity range for growth is $1.0-7.5 \% \mathrm{NaCl}$ as well as $15-100 \%$ seawater [1]. Yeast extract, peptone or starch is required for growth [1]. Ampicillin $(10 \mu \mathrm{g})$, chloramphenicol $(30 \mu \mathrm{g})$, erythromycin $(10 \mu \mathrm{g})$, penicillin $\mathrm{G}$ (2U), rifampicin $(10 \mu \mathrm{g})$, streptomycin $(10 \mu \mathrm{g})$, tetracycline $(30 \mu \mathrm{g})$ and polymyxin $\mathrm{B}(300 \mathrm{U})$ inhibited growth whereas cells were resistant to kanamycin $(10 \mu \mathrm{g})$, gentamycin sulphate $(10 \mu \mathrm{g})$ and spectinomycin $(10 \mu \mathrm{g})$ [1]. Cells contain oxidase, catalase and alkaline phosphatase [1].

\section{Chemotaxonomy}

The fatty-acid profile of strain UST20020801 ${ }^{\mathrm{T}}$ differs significantly from those of other members of the Cryomorphaceae [1]. The principal cellular fatty acids of strain UST20020801 ${ }^{\mathrm{T}}$ were the following saturated branched-chain fatty acids: iso- $\mathrm{C}_{15: 0} \mathrm{G}$ (28.0\%), iso- $\mathrm{C}_{15: 0}(18.7 \%)$, iso- $\mathrm{C}_{17: 0 \text { 3-он }}(18.1 \%)$, iso$\mathrm{C}_{17: 1 \omega 9 \mathrm{c}}(7.3 \%)$, iso- $\mathrm{C}_{15: 0}$ 3-0H $(4.9 \%)$, and a summed feature containing iso- $\mathrm{C}_{15: 0}$ 2-0H and/or $\mathrm{C}_{16: 1 \omega 7 \mathrm{c}}$ (10.0\%) [1]. Strain UST20020801 ${ }^{\mathrm{T}}$ had the highest level of iso- $\mathrm{C}_{17: 0}$ 3-0H within Cryomorphaceae. Compared with other members of the Cryomorphaceae, the strain most similar to strain UST20020801 with respect to the content of straight-chain fatty acids and branched-chain hydroxy fatty acids is Cryomorpha ignava 1-22 ${ }^{\mathrm{T}}$ [1]. In addition to phosphatidyl-ethanolamine as major polar lipid, six unidentified lipids, one unidentified aminolipid, one unidentified aminophospholipid and one unidentified glycolipid were found in strain UST20020801T [15]. MK-6 was detected as a major respiratory quinone in strain UST20020801T [1].

\section{Genome sequencing and annotation Genome project history}

This organism was selected for sequencing on the basis of its phylogenetic position [41], and is part of the Genomic Encyclopedia of Bacteria and Archaea project [42]. The genome project is deposited in the Genomes On Line Database [27] and the complete genome sequence is deposited in GenBank. Sequencing, finishing and annotation were performed by the DOE Joint Genome Institute (JGI). A summary of the project information is shown in Table 2. 


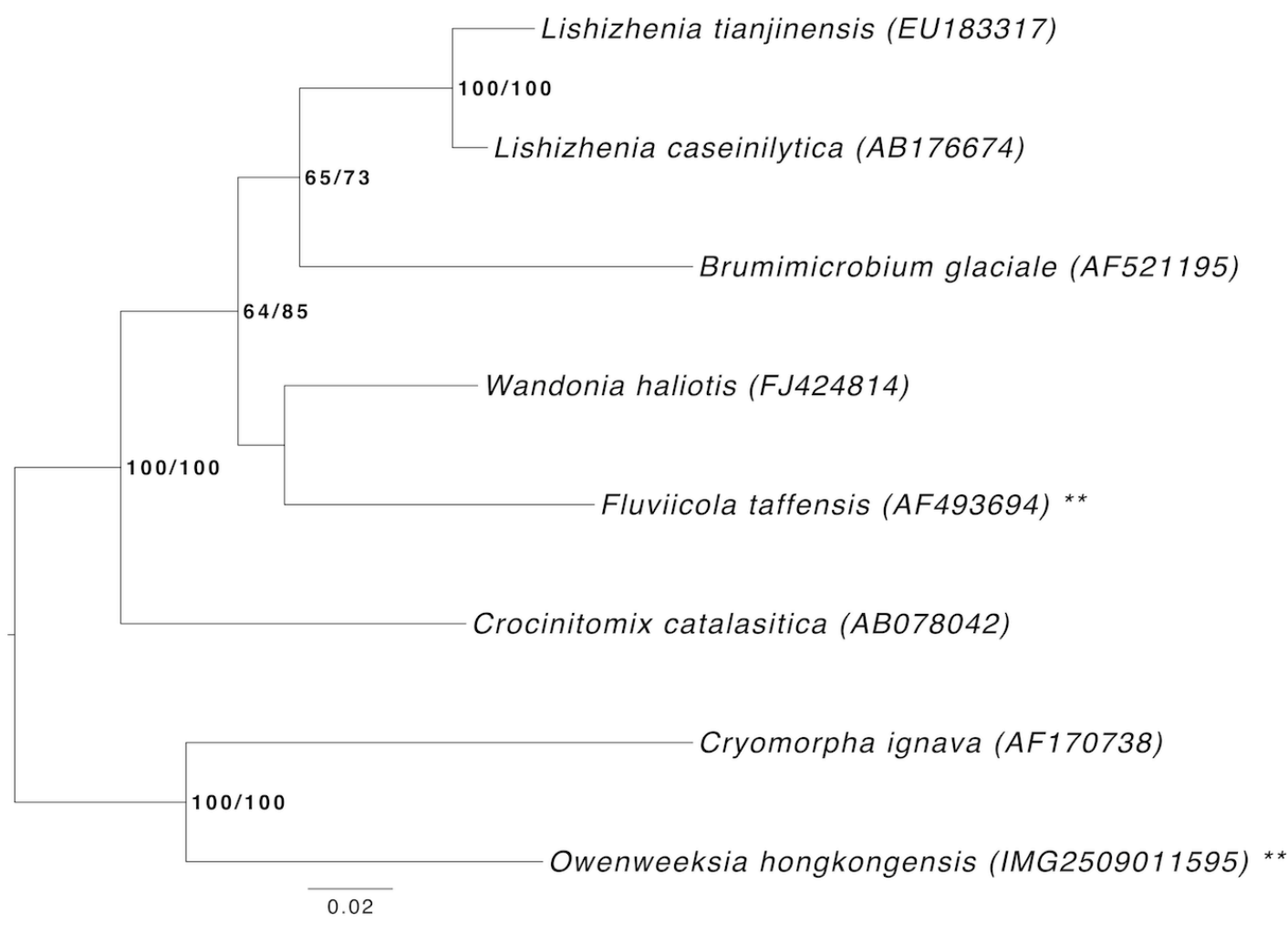

Figure 1. Phylogenetic tree highlighting the position of $O$. hongkongensis relative to the type strains of the other species within the family Cryomorphaceae. The tree was inferred from 1,409 aligned characters $[21,22]$ of the $16 \mathrm{~S}$ rRNA gene sequence under the maximum likelihood (ML) criterion [23]. Rooting was done initially using the midpoint method [24] and then checked for its agreement with the current classification (Table 1). The branches are scaled in terms of the expected number of substitutions per site. Numbers adjacent to the branches are support values from $400 \mathrm{ML}$ bootstrap replicates [25] (left) and from 1,000 maximum-parsimony bootstrap replicates [26] (right) if larger than 60\%. Lineages with type strain genome sequencing projects registered in GOLD [27] are labeled with one asterisk, those also listed as 'Complete and Published' with two asterisks [28].

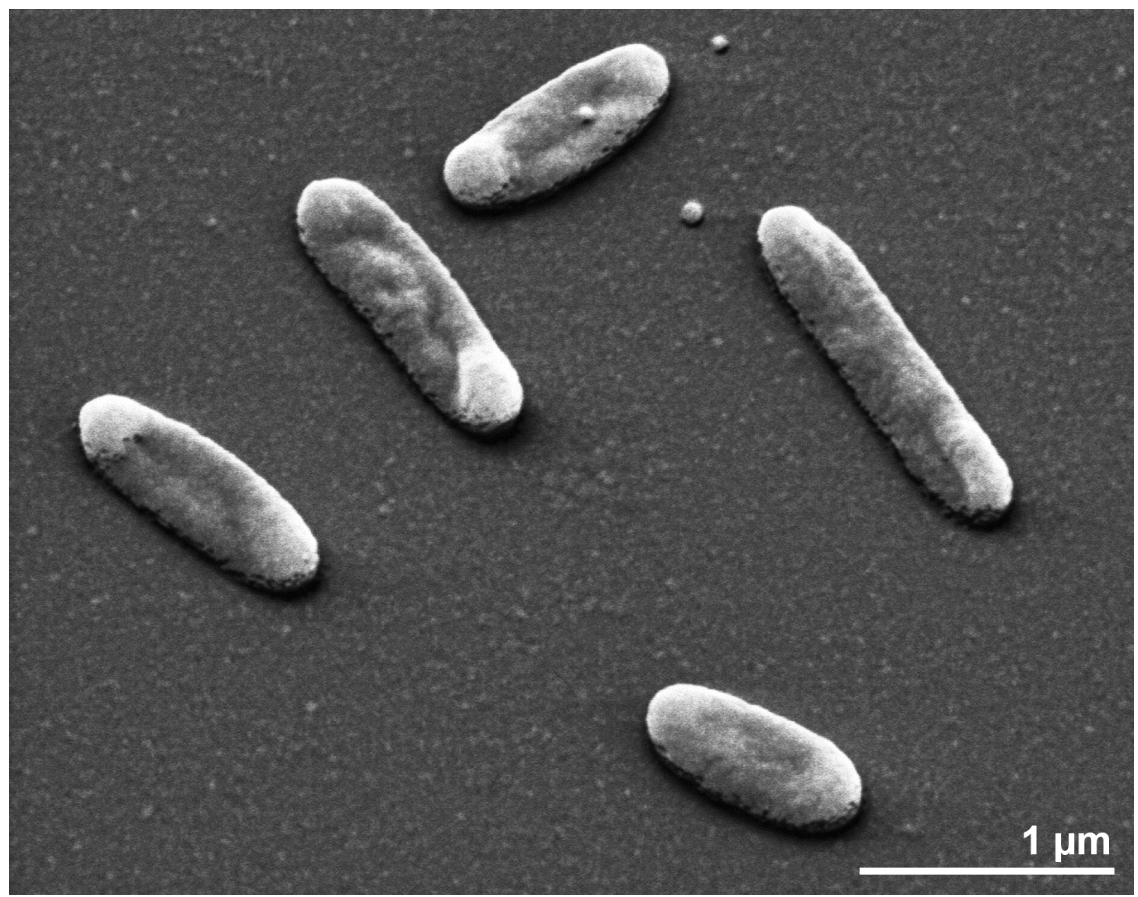

Figure 2. Scanning electron micrograph of $O$. hongkongensis UST20020801 
Table 1. Classification and general features of $O$. hongkongensis UST20020801 ${ }^{\top}$ according to the MIGS recommendations [29] and NamesforLife [30].

\begin{tabular}{|c|c|c|c|}
\hline MIGS ID & Property & Term & Evidence code \\
\hline & \multirow{8}{*}{ Current classification } & Domain Bacteria & TAS [31] \\
\hline & & Phylum Bacteroidetes & TAs [32,33] \\
\hline & & Class Flavobacteria & TAS [34-36] \\
\hline & & Order Flavobacteriales & TAS $[33,37,38]$ \\
\hline & & Family Cryomorphaceae & TAS [12] \\
\hline & & Genus Owenweeksia & TAS [1] \\
\hline & & Species Owenweeksia hongkongensis & TAS [1] \\
\hline & & Strain UST20020801 & TAS [1] \\
\hline & Gram stain & negative & TAS [1] \\
\hline & Cell shape & rod-shaped & TAS [1] \\
\hline & Motility & motile & TAS [1] \\
\hline & Sporulation & none & TAS [1] \\
\hline & Temperature range & mesophile, $4-37^{\circ} \mathrm{C}$ & TAS [1] \\
\hline & Optimum temperature & $25-33^{\circ} \mathrm{C}$ & TAS [1] \\
\hline & Salinity & $1.0-7.5 \% \mathrm{NaCl}(\mathrm{w} / \mathrm{v}), 0-100 \%$ sea water & TAS [1] \\
\hline \multirow[t]{3}{*}{ MIGS-22 } & Oxygen requirement & aerobe & TAS [1] \\
\hline & Carbon source & yeast extract, peptone, starch & TAS [1] \\
\hline & Energy metabolism & heterotroph & TAS [1] \\
\hline MIGS-6 & Habitat & Seawater & TAS [1] \\
\hline MIGS-15 & Biotic relationship & free-living & TAS [1] \\
\hline \multirow[t]{2}{*}{ MIGS-14 } & Pathogenicity & none & NAS \\
\hline & Biosafety level & 1 & TAS [39] \\
\hline MIGS-23.1 & Isolation & sea water (sand-filtered) & TAS [1] \\
\hline MIGS-4 & Geographic location & Port Shelter, Hong Kong, China & TAS [1] \\
\hline MIGS-5 & Sample collection time & August 2002 & TAS [1] \\
\hline MIGS-4.1 & Latitude & 22.341 & NAS \\
\hline MIGS-4.2 & Longitude & 114.281 & NAS \\
\hline MIGS-4.3 & Depth & $5 \mathrm{~m}$ & TAS [1] \\
\hline MIGS-4.4 & Altitude & not reported & \\
\hline
\end{tabular}

Evidence codes - TAS: Traceable Author Statement (i.e., a direct report exists in the literature); NAS: Non-traceable Author Statement (i.e., not directly observed for the living, isolated sample, but based on a generally accepted property for the species, or anecdotal evidence). Evidence codes are from the Gene Ontology project [40]. 
Table 2. Genome sequencing project information

\begin{tabular}{lll}
\hline MIGS ID & Property & Term \\
\hline MIGS-31 & Finishing quality & Finished \\
& & Three genomic libraries: one 454 pyrosequence standard library, one \\
MIGS-28 & Libraries used & 454 PE library (8.5 kb insert size), one Illumina library \\
MIGS-29 & Sequencing platforms & Illumina GAii, 454 GS FLX Titanium \\
MIGS-31.2 & Sequencing coverage & 300.0 $\times$ Illumina; 8.6 × pyrosequence \\
MIGS-30 & Assemblers & Newbler version 2.3-PreRelease-6/30/2009, Velvet 1.0.13, phrap \\
MIGS-32 & Gene calling method & version SPS - 4.24 \\
& INSDC ID & CP003156 \\
& GenBank Date of Release & June 15, 2012 \\
& GOLD ID & Gc02043 \\
& NCBI project ID & 65297 \\
& Database: IMG-GEBA & 2508501098 \\
& Source material identifier & DSM 17368 \\
& Project relevance & Tree of Life, GEBA \\
\hline
\end{tabular}

\section{Growth conditions and DNA isolation}

O. hongkongensis strain UST20020801T, DSM 17368, was grown in DSMZ medium 1168 (YPS medium) [43] at $30^{\circ} \mathrm{C}$. DNA was isolated from $0.5-1$ $\mathrm{g}$ of cell paste using Jetflex Genomic DNA Purification kit (GENOMED 600100) following the standard protocol as recommended by the manufacturer with an extended cell-lysis procedure, i.e. incubation with additional $80 \mu \mathrm{l}$ protease $\mathrm{K}$ for one hour at $58^{\circ} \mathrm{C}$. DNA is available through the DNA Bank Network [44].

\section{Genome sequencing and assembly}

The genome was sequenced using a combination of Illumina and 454 sequencing platforms. All general aspects of library construction and sequencing can be found at the JGI website [45]. Pyrosequencing reads were assembled using the Newbler assembler (Roche). The initial Newbler assembly, consisting of 39 contigs in one scaffold, was converted into a phrap [46] assembly by making fake reads from the consensus to collect the read pairs in the 454 paired end library. Illumina GAii sequencing data $(5,738.3$ $\mathrm{Mb}$ ) was assembled with Velvet [47] and the consensus sequences were shredded into $1.5 \mathrm{~kb}$ overlapped fake reads and assembled together with the 454 data. The 454 draft assembly was based on 81.1 Mb 454 draft data and all of the 454 paired end data. Newbler parameters are -consed -a 50 -l 350 -g -m $\mathrm{ml} 20$. The Phred/Phrap/Consed software package [46] was used for sequence assembly and quality assessment in the subsequent finishing process. After the shotgun stage, reads were assembled with parallel phrap (High Performance Software, LLC).
Possible mis-assemblies were corrected with gapResolution [45], Dupfinisher [48], or sequencing cloned bridging PCR fragments with subcloning. Gaps between contigs were closed by editing in Consed, by PCR and by Bubble PCR primer walks (J.F. Chang, unpublished). A total of 58 additional reactions were necessary to close gaps and to raise the quality of the finished sequence. Illumina reads were also used to correct potential base errors and increase consensus quality using the software Polisher developed at JGI [49]. The error rate of the completed genome sequence is less than 1 in 100,000. Together, the combination of the Illumina and 454 sequencing platforms provided $308.6 \mathrm{x}$ coverage of the genome. The final assembly contained 291,505 pyrosequence and 75,503,620 Illumina reads.

\section{Genome annotation}

Genes were identified using Prodigal [50] as part of the Oak Ridge National Laboratory genomeannotation pipeline, followed by a round of manual curation using the JGI GenePRIMP pipeline [51]. The predicted CDSs were translated and used to search the National Center for Biotechnology Information (NCBI) non-redundant database, UniProt, TIGRFam, Pfam, PRIAM, KEGG, COG, and InterPro databases. These data sources were combined to assert a product description for each predicted protein. Additional gene prediction analysis and functional annotation was performed within the Integrated Microbial Genomes - Expert Review (IMG-ER) platform [52]. 


\section{Genome properties}

The genome consists of a 4,000,057 bp long circular chromosome with a G+C content of $40.2 \%$ (Figure 3 and Table 3). Of the 3,563 genes predicted, 3,518 were protein-coding genes, and 45
RNAs; 33 pseudogenes were also identified. The majority of the protein-coding genes (67.9\%) were assigned a putative function while the remaining ones were annotated as hypothetical proteins. The distribution of genes into COGs functional categories is presented in Table 4.

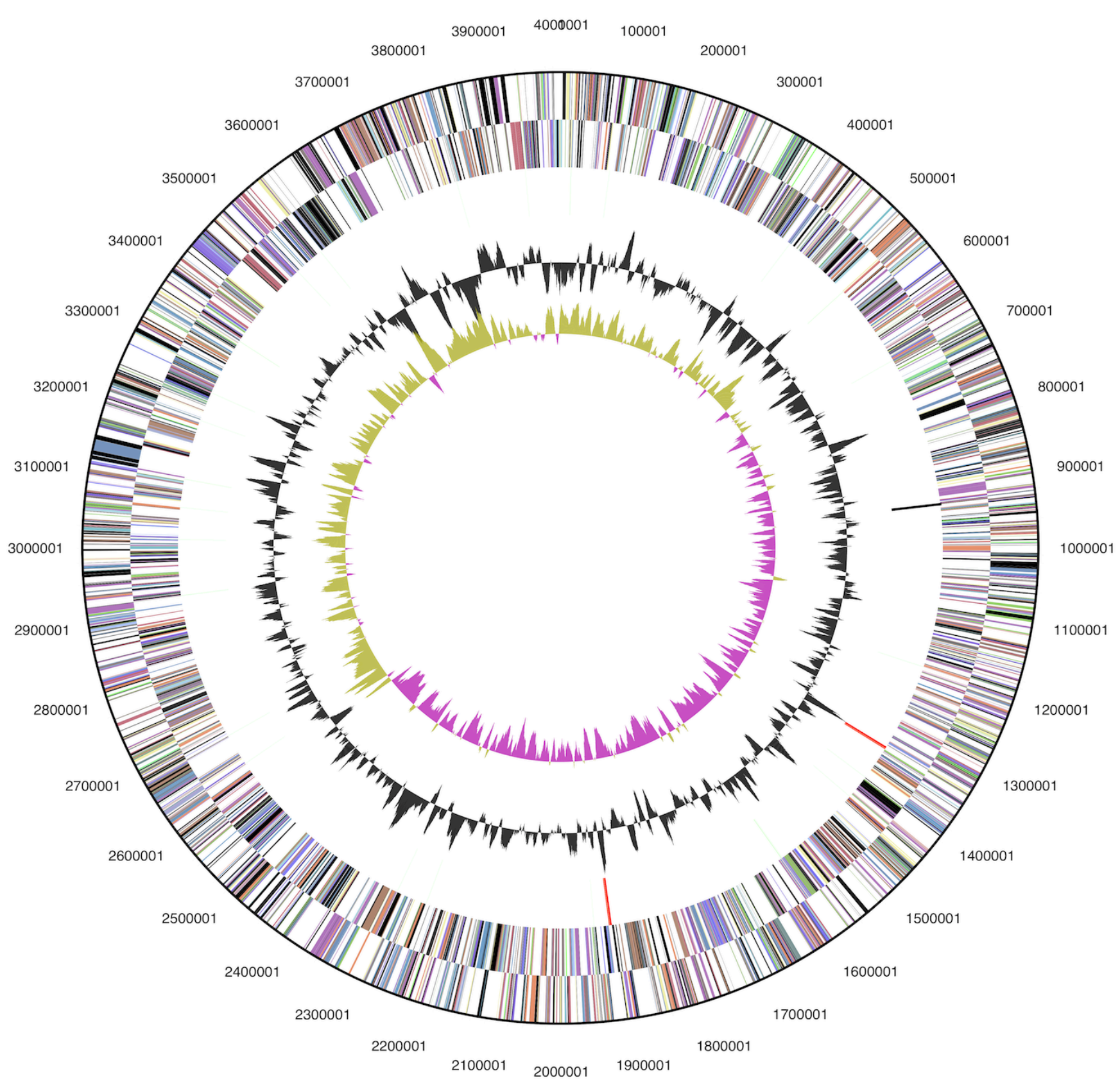

Figure 3. Graphical map of the chromosome. From outside to center: Genes on forward strand (colored by COG categories), Genes on reverse strand (colored by COG categories), RNA genes (tRNAs green, rRNAs red, other RNAs black), GC content (black), GC skew (purple/olive). 
Table 3. Genome Statistics

\begin{tabular}{lrr}
\hline Attribute & Value & \% of Total \\
\hline Genome size (bp) & $4,000,057$ & $100.00 \%$ \\
DNA coding region (bp) & $3,661,831$ & $91.54 \%$ \\
DNA G+C content (bp) & $1,609,363$ & $40.23 \%$ \\
Number of replicons & 1 & \\
Extrachromosomal elements & 0 & \\
Total genes & 3,563 & $100.00 \%$ \\
RNA genes & 45 & $1.26 \%$ \\
rRNA operons & 2 & \\
tRNA genes & 38 & $0.93 \%$ \\
Protein-coding genes & 3,518 & $98.74 \%$ \\
Pseudo genes & 33 & $0.93 \%$ \\
Genes with function prediction (proteins) & 2,301 & $64.58 \%$ \\
Genes in paralog clusters & 1,516 & $42.55 \%$ \\
Genes assigned to COGs & 2,279 & $63.96 \%$ \\
Genes assigned Pfam domains & 2,263 & $66.32 \%$ \\
Genes with signal peptides & 1,095 & $30.73 \%$ \\
Genes with transmembrane helices & 822 & $23.07 \%$ \\
CRISPR repeats & 0 & \\
\hline
\end{tabular}

Table 4. Number of genes associated with the general COG functional categories

\begin{tabular}{crrl}
\hline Code & value & \%age & Description \\
\hline J & 155 & 6.2 & Translation, ribosomal structure and biogenesis \\
A & 0 & 0.0 & RNA processing and modification \\
K & 139 & 5.6 & Transcription \\
L & 141 & 5.7 & Replication, recombination and repair \\
B & 1 & 0.0 & Chromatin structure and dynamics \\
D & 33 & 1.3 & Cell cycle control, cell division, chromosome partitioning \\
Y & 0 & 0.0 & Nuclear structure \\
V & 54 & 2.2 & Defense mechanisms \\
T & 147 & 5.9 & Signal transduction mechanisms \\
M & 233 & 9.3 & Cell wall/membrane biogenesis \\
N & 13 & 0.5 & Cell motility \\
Z & 3 & 0.1 & Cytoskeleton \\
W & 0 & 0.0 & Extracellular structures \\
U & 45 & 1.8 & Intracellular trafficking and secretion, and vesicular transport \\
O & 107 & 4.3 & Posttranslational modification, protein turnover, chaperones \\
C & 116 & 4.7 & Energy production and conversion \\
G & 71 & 2.9 & Carbohydrate transport and metabolism \\
E & 181 & 7.3 & Amino acid transport and metabolism \\
F & 57 & 2.3 & Nucleotide transport and metabolism \\
H & 115 & 4.6 & Coenzyme transport and metabolism \\
I & 114 & 4.6 & Lipid transport and metabolism \\
P & 127 & 5.1 & Inorganic ion transport and metabolism \\
Q & 54 & 2.2 & Secondary metabolites biosynthesis, transport and catabolism \\
R & 337 & 13.5 & General function prediction only \\
S & 251 & 10.1 & Function unknown \\
- & 1,284 & 36.0 & Not in COGs \\
\hline
\end{tabular}




\section{Insights into the genome sequence}

Genome analysis of strain UST20020801 ${ }^{\mathrm{T}}$ revealed the presence of genes encoding an arylsulfatase A family protein (Oweho_0043), a bacteriophytochrome (light-regulated signal transduction histidine kinase (Oweho_0350), a cytochrome c2 and a cytochrome c oxidase cbb3 type (Oweho_2085)). Additional gene sequences of interest encode a homogenisate 1,2-dioxigenase (Oweho_2010), a haloacid dehalogenase superfamily

\section{Acknowledgements}

The authors would like to gratefully acknowledge the help of Helga Pomrenke for growing O. hongkongensis cultures and Evelyne-Marie Brambilla for DNA extraction and quality control (both at DSMZ). This work was performed under the auspices of the US Department of Energy Office of Science, Biological and Environmental Research Program, and by the University of California, Lawrence Berkeley National Laboratory under contract

\section{References}

1. Lau KWK, Ng CYM, Ren J, Lau SCL, Qian PY, Wong PK, Lau TC, Wu M. Owenweeksia hongkongensis gen. nov., sp. nov., a novel marine bacterium of the phylum 'Bacteroidetes'. Int I Syst Evol Microbiol 2005; 55:1051-1057. PubMed http://dx.doi.org/10.1099/ijs.0.63155-0

2. Delong EF, Franks DG, Alldredge AL. Phylogenetic diversity of aggregate-attached versus freeliving marine bacterial assemblages. Limnol Oceanogr 1993; 38:924-934. http://dx.doi.org/10.4319/lo.1993.38.5.0924

3. Rath J, Wu KY, Herndl GJ, DeLong EF. High phylogenetic diversity in a marine-snow-associated bacterial assemblage. Aquat Microb Ecol 1998; 14:261-269. http://dx.doi.org/10.3354/ame014261

4. Pinhassi J, Sala MM, Havskum H, Peters F, Guadayol O, Malits A, Marrasé C. Changes in bacterioplancton composition under different phytoplankton regimes. Appl Environ Microbiol 2004; 70:6753-6766. PubMed http://dx.doi.org/10.1128/AEM.70.11.6753$\underline{6766.2004}$

5. Riemann L, Steward GF, Azam F. Dynamics of bacterial community composition and activity during a mesocosm diatom bloom. App/ Environ Microbiol 2000; 66:578-587. PubMed http://dx.doi.org/10.1128/AEM.66.2.578$\underline{587.2000}$ protein (Oweho_2094) as well as a 2-haloalkanoic acid dehalogenase type II (Oweho_2503). The presence of these genes could indicate that strain UST20020801 ${ }^{\mathrm{T}}$ plays a role in the respiratory degradation of recalcitrant compounds in its ecological niche. Further, a light-dependent regulation of metabolic activities using bacteriophytochrome as a sensor seems to be possible.

No. DE-AC02-05CH11231, Lawrence Livermore National Laboratory under Contract No. DE-AC5207NA27344, and Los Alamos National Laboratory under contract No. DE-AC02-06NA25396, UT-Battelle and Oak Ridge National Laboratory under contract DEAC05-000R22725, as well as German Research Foundation (DFG) INST 599/1-2 and Transregio-SFB 51 Roseobacter.

6. Cottrell MT, Kirchman DL. Natural assemblages of marine proteobacteria and members of the Cytophaga-Flavobacter cluster consuming lowand high-molecular weight dissolved organic matter. Appl Environ Microbiol 2000; 66:16921697. PubMed

http://dx.doi.org/10.1128/AEM.66.4.1692$\underline{1697.2000}$

7. Kirchman DL. The ecology of CytophagaFlavobacteria in aquatic environments. FEMS Microbiol Ecol 2002; 39:91-100. PubMed

8. Anderson KL, Salyers AA. Biochemical evidence that starch breakdown by Bacteroides thetaiotaomicron involves outer membrane starch binding sites and periplasmatic starch-degrading enzymes. / Bacterio/ 1989; 171:3192-3198. PubMed

9. Anderson KL, Salyers AA. Genetic evidence that outer membrane binding of starch is required for starch utilization by Bacteroides thetaiotaomicron. J Bacteriol 1989; 171:31993204. PubMed

10. Bauer $M$, Kube $M$, Teeling $H$, Richter $M$, Lombardot T, Allers E, Würdemann CA, Quast C, Kuhl $\mathrm{H}$, Knaust $\mathrm{F}$, et al. Whole genome analysis of the marine Bacteroidetes 'Gramella forsetii' reveals adaption to degradation of polymeric organic matter. Environ Microbiol 2006; 8:2201-2213. PubMed http://dx.doi.org/10.1111/j.14622920.2006.01152.x 
11. González JM, Fernández-Gómez B, FernàndezGuerra A, Gómez-Consarnau L, Sánchez O, CollLladó M, Del Campo J, Escudero L, RodriguezMartinez R, Alsonso-Sáez L, et al. Genome analysis of the proteorhodopsin-containing marine bacterium Polaribacter sp. MED152 (Flavobacteria). Proc Natl Acad Sci USA 2008; 105:8724-8729. PubMed http://dx.doi.org/10.1073/pnas.0712027105

12. Bowman JP, Mancuso Nichols C, Gibson JAE. Algoriphagus ratkowskyi gen. nov., sp. nov., Brumimicrobium glaciale gen. nov., sp. nov., Cryomorpha ignava gen. nov., sp. nov. and Crocinitomix catalasitica gen. nov., sp. nov., novel flavobacteria isolated from various polar habitats. Int / Syst Evol Microbiol 2003; 53:13431355. PubMed http://dx.doi.org/10.1099/ijs.0.02553-0

13. Lau KW, Ren J, Wai NL, Qian PY, Wong PK, Wu M. Lishizhenia caseinilytica gen. nov., sp. nov., a marine bacterium of the phylum Bacteroidetes. Int J Syst Evol Microbiol 2006; 56:2317-2322. PubMed http://dx.doi.org/10.1099/ijs.0.64415-0

14. Lee DH, Choi EK, Moon SR, Ahn S, Lee YS, Jung JS, Jeon CO, Whang KS, Kahng HY. Wandonia haliotis gen. nov., sp. nov., a marine bacterium of the family Cryomorphaceae, phylum

Bacteroidetes. Int I Syst Evol Microbiol 2010;

60:510-514. PubMed http://dx.doi.org/10.1099/ijs.0.012674-0

15. Zhou Y, Su J, Lai Q, Li X, Yang X, Dong P, Zheng T. Phaeocystidibacter luteus gen. nov. sp. nov., a new member of the family Cryomorphaceae isolated from the marine alga Phaeocystis globosa and emended description of Owenweeksia hongkongensis. Int I Syst Evol Microbiol 2012. PubMed http://dx.doi.org/10.1099/ijs.0.030254-0

16. O'Sullivan LA, Rinna J, Humphreys G, Weightman AJ, Fry JC. Fluviicola taffensis gen. nov., sp. nov., a novel freshwater bacterium of the family Cryomorphaceae in the Phylum 'Bacteroidetes'. Int I Syst Evol Microbiol 2005; 55:2189-2194. PubMed http://dx.doi.org/10.1099/ijs.0.63736-0

17. Altschul SF, Gish W, Miller W, Myers EW, Lipman DJ. Basic local alignment search tool. J Mol Biol 1990; 215:403-410. PubMed

18. Korf I, Yandell M, Bedell J. BLAST, O'Reilly, Sebastopol, 2003.

19. DeSantis TZ, Hugenholtz $P$, Larsen $N$, Rojas $M$, Brodie EL, Keller K, Huber T, Dalevi D, Hu P, Andersen GL. Greengenes, a chimera-checked
16S rRNA gene database and workbench compatible with ARB. Appl Environ Microbiol 2006; 72:5069-5072. PubMed http://dx.doi.org/10.1128/AEM.03006-05

20. Porter MF. An algorithm for suffix stripping. Program: electronic library and information systems 1980; 14:130-137.

21. Lee C, Grasso C, Sharlow MF. Multiple sequence alignment using partial order graphs. Bioinformatics 2002; 18:452-464. PubMed

http://dx.doi.org/10.1093/bioinformatics/18.3.452

22. Castresana J. Selection of conserved blocks from multiple alignments for their use in phylogenetic analysis. Mol Biol Evol 2000; 17:540-552. PubMed

http://dx.doi.org/10.1093/oxfordjournals.molbev.a 026334

23. Stamatakis A, Hoover P, Rougemont J. A rapid bootstrap algorithm for the RAxML web servers. Syst Biol 2008; 57:758-771. PubMed http://dx.doi.org/10.1080/10635150802429642

24. Hess PN, De Moraes Russo CA. An empirical test of the midpoint rooting method. Biol / Linn SoC Lond 2007; 92:669-674.

http://dx.doi.org/10.1111/j.10958312.2007.00864.x

25. Pattengale ND, Alipour M, Bininda-Emonds ORP, Moret BME, Stamatakis A. How many bootstrap replicates are necessary? Lect Notes Comput Sci 2009; 5541:184-200. http://dx.doi.org/10.1007/978-3-642-02008-7_13

26. Swofford DL. PAUP*: Phylogenetic Analysis Using Parsimony (*and Other Methods), Version 4.0 b10. Sinauer Associates, Sunderland, 2002.

27. Pagani I, Liolios K, Jansson J, Chen IM, Smirnova T, Nosrat B, Markowitz VM, Kyrpides NC. The Genomes OnLine Database (GOLD) v.4: status of genomic and metagenomic projects and their associated metadata. Nucleic Acids Res 2012; 40:D571-D579. PubMed http://dx.doi.org/10.1093/nar/gkr1100

28. Woyke T, Chertkov O, Lapidus A, Nolan M, Lucas S, Glavina Del Rio T, Tice H, Cheng JF, Tapia $\mathrm{R}$, Han C, et al. Complete genome sequence of the gliding freshwater bacterium Fluviicola taffensis type strain (RW262 ${ }^{\top}$ ). Stand Genomic Sci 2011; 5:21-29. PubMed http://dx.doi.org/10.4056/sigs.2124912

29. Field D, Garrity G, Gray T, Morrison N, Selengut J, Sterk P, Tatusova T, Thomson N, Allen MJ, Angiuoli SV, et al. The minimum information 
about a genome sequence (MIGS) specification. Nat Biotechnol 2008; 26:541-547. PubMed http://dx.doi.org/10.1038/nbt1360

30. Garrity G. NamesforLife. BrowserTool takes expertise out of the database and puts it right in the browser. Microbiol Today 2010; 37:9.

31. Woese CR, Kandler O, Wheelis ML. Towards a natural system of organisms. Proposal for the domains Archaea and Bacteria. Proc Natl Acad Sci USA 1990; 87:4576-4579. PubMed http://dx.doi.org/10.1073/pnas.87.12.4576

32. Krieg NR, Ludwig W, Euzéby J, Whitman WB. Phylum XIV. Bacteroidetes phyl. nov. In: Krieg NR, Staley JT, Brown DR, Hedlund BP, Paster BJ, Ward NL, Ludwig W, Whitman WB (eds), Bergey's Manual of Systematic Bacteriology, Second Edition, Volume 4, Springer, New York, 2011, p. 25.

33. Validation List No. 143. [PubMed]. Int / Syst Evol Microbiol 2012; 62:1-4.

34. Bernardet JF. Class II. Flavobacteria class. nov. In: Krieg NR, Staley JT, Brown DR, Hedlund BP, Paster BJ, Ward NL, Ludwig W, Whitman WB (eds), Bergey's Manual of Systematic Bacteriology, Second Edition, Volume 4, Springer, New York, 2011, p. 105.

35. Ludwig W, Euzeby J, Whitman WG. Draft taxonomic outline of the Bacteroidetes, Planctomycetes, Chlamydiae, Spirochaetes, Fibrobacteres, Fusobacteria, Acidobacteria, Verrucomicrobia, Dictyoglomi, and Gemmatimonadetes.

36. Judicial Commission of the International Committee on Systematics of Prokaryotes. The nomenclatural types of the orders Acholeplasmatales, Halanaerobiales, Halobacteriales, Methanobacteriales, Methanococcales, Methanomicrobiales, Planctomycetales, Prochlorales, Sulfolobales, Thermococcales, Thermoproteales and Verrucomicrobiales are the genera Acholeplasma, Halanaerobium, Halobacterium, Methanobacterium, Methanococcus, Methanomicrobium, Planctomyces, Prochloron, Sulfolobus, Thermococcus, Thermoproteus and Verrucomicrobium, respectively. Opinion 79. Int I Syst Evol Microbiol 2005.

37. Bernardet JF. Order I. Flavobacteriales ord. nov. In: Krieg NR, Staley JT, Brown DR, Hedlund BP, Paster BJ, Ward NL, Ludwig W, Whitman WB (eds), Bergey's Manual of Systematic Bacteriolo- gy, Second Edition, Volume 4, Springer, New York, 2011, p. 105.

38. Errata: List of new names and new combinations previously effectively, but not validly, published Validation List No. 143. Int I Syst Evol Microbiol 2012; 62:1016.

http://dx.doi.org/10.1099/ijs.0.68147-0

39. BAuA. 2010, Classification of bacteria and archaea in risk groups. http://www.baua.de TRBA 466, p. 158.

40. Ashburner M, Ball CA, Blake JA, Botstein D, Butler H, Cherry JM, Davis AP, Dolinski K, Dwight SS, Eppig JT, et al. Gene ontology: tool for the unification of biology. The Gene Ontology Consortium. Nat Genet 2000; 25:25-29. PubMed http://dx.doi.org/10.1038/75556

41. Klenk HP, Göker M. En route to a genome-based classification of Archaea and Bacteria? Syst Appl Microbiol 2010; 33:175-182. PubMed http://dx.doi.org/10.1016/j.syapm.2010.03.003

42. Wu D, Hugenholtz P, Mavromatis K, Pukall R, Dalin E, Ivanova NN, Kunin V, Goodwin L, Wu $M$, Tindall BJ, et al. A phylogeny-driven Genomic Encyclopaedia of Bacteria and Archaea. Nature 2009; 462:1056-1060. PubMed http://dx.doi.org/10.1038/nature08656

43. List of growth media used at DSMZ: http://www.dsmz.de/catalogues/cataloguemicroorganisms/culture-technology/list-of-mediafor-microorganisms.html.

44. Gemeinholzer B, Dröge $G$, Zetzsche $H$, Haszprunar G, Klenk HP, Güntsch A, Berendsohn WG, Wägele JW. The DNA Bank Network: the start from a German initiative. Biopreserv Biobank 2011; 9:51-55.

http://dx.doi.org/10.1089/bio.2010.0029

45. The DOE Joint Genome Institute. http://www.jgi.doe.gov

46. Phrap and Phred for Windows. MacOS, Linux, and Unix. http://www.phrap.com

47. Zerbino DR, Birney E. Velvet: algorithms for de novo short read assembly using de Bruijn graphs. Genome Res 2008; 18:821-829. PubMed http://dx.doi.org/10.1101/gr.074492.107

48. Han C, Chain P. Finishing repeat regions automatically with Dupfinisher. In: Proceedings of the 2006 international conference on bioinformatics \& computational biology. Arabnia HR, Valafar $\mathrm{H}$ (eds), CSREA Press. June 26-29, 2006: 141-146. 
49. Lapidus A, LaButti K, Foster B, Lowry S, Trong S, Goltsman E. POLISHER: An effective tool for using ultra short reads in microbial genome assembly and finishing. AGBT, Marco Island, FL, 2008.

50. Hyatt $\mathrm{D}, \mathrm{Chen} \mathrm{GL}$, Locascio PF, Land ML, Larimer FW, Hauser LJ. Prodigal Prokaryotic Dynamic Programming Genefinding Algorithm. BMC Bioinformatics 2010; 11:119. PubMed

http://dx.doi.org/10.1186/1471-2105-11-119
51. Pati A, Ivanova N, Mikhailova N, Ovchinikova G, Hooper SD, Lykidis A, Kyrpides NC. GenePRIMP: A Gene Prediction Improvement Pipeline for microbial genomes. Nat Methods 2010; 7:455-457. PubMed http://dx.doi.org/10.1038/nmeth.1457

52. Markowitz VM, Ivanova NN, Chen IMA, Chu K, Kyrpides NC. IMG ER: a system for microbial genome annotation expert review and curation. Bioinformatics 2009; 25:2271-2278. PubMed http://dx.doi.org/10.1093/bioinformatics/btp393 